\title{
Zika related microcephaly may appear after birth, study finds
}

\author{
Michael McCarthy
}

Seattle

Infants exposed to the Zika virus in utero may develop Zika associated microcephaly and other neurological complications after birth, researchers from Brazil and the United States warn. "The absence of microcephaly at birth does not exclude congenital Zika virus infection or the presence of Zika-related brain and other abnormalities," they wrote.

Their report, which appeared in the US Centers for Disease Control and Prevention's Morbidity and Mortality Weekly Report, ${ }^{1}$ described the cases of 13 infants born in Pernambuco and Ceará, two states in northeastern Brazil. At birth all of the children—nine male and four female—had normal head size. However, 11 of the infants came to clinical attention because their head circumferences, which had been established by the Brazilian Ministry of Health as requiring further evaluation for possible congenital Zika infection, were $33 \mathrm{~cm}$ before 2 December 2015 and were $32 \mathrm{~cm}$ after that date (gestational age $\geq 37$ weeks). The remaining two infants were referred for evaluation at ages 5 and 7 months because of concerns about their neurodevelopment.

Although these 11 infants did not have microcephaly at birth, craniofacial disproportion was noted in six, three had redundant skin on the scalp, and three had hip dysplasia, including one with arthrogryposis who had bilateral dislocated hips.

Laboratory evidence of congenital Zika infection was defined as negative laboratory test results for five infectious causes of congenital microcephaly - toxoplasmosis, cytomegalovirus, rubella, syphilis, and HIV - and positive serologic evidence of Zika infection.
Neuroimaging showed malformations of cortical development, subcortical calcifications, and evidence of decreased brain volume, with ventriculomegaly in all infants. Dysphagia was found in 10 of 13 , seven had a diagnosis of epilepsy, and three had chorioretinal abnormalities. The infants were too young to be assessed for cognitive deficits.

The researchers wrote that pathogenesis of postnatal microcephaly is not known but that the decrease in head growth may be a consequence of earlier in utero destruction of neuroprogenitor or other neural cells or a persistent inflammatory response. Continued infection of neural cells was less likely, since Zika virus RT-PCR (reverse transcription polymerase chain reaction) tests conducted on cerebral spinal fluid samples from seven of the cases were all negative.

The researchers concluded, "These findings support the recommendation for comprehensive medical and developmental follow-up of infants exposed to Zika virus prenatally. Early neuroimaging might identify brain abnormalities related to congenital Zika infection even among infants with a normal head circumference."

1 Van der Linden V, Pessoa A, Dobyns W, et al Description of 13 infants born during October 2015-January 2016 with congenital Zika virus infection without microcephaly at birth-Brazil. MMWR Morb Mortal Wkly Rep 2016; published online 22 Nov. doi:10.15585/ mmwr.mm6547e2.

Published by the BMJ Publishing Group Limited. For permission to use (where not already granted under a licence) please go to http://group.bmj.com/group/rights-licensing/ permissions 